\title{
When my patient doesn't want my help
}

\section{Neema K. Khonsari, MD}

S ince beginning my psychiatry residency, I have come to dread situations in which I feel like the antagonist in my patient's life. These are moments when, due to psychiatric illness or intoxication, my patient does not want my help. In these situations, the patient's condition may prevent shared decision-making to determine the best care for them. I experienced such a situation on my first day of residency, and that encounter taught me several valuable lessons.

\section{An anxiety-filled first day}

While working with my attending physician in a psychiatric emergency department, we met with a patient who had become agitated and was threatening staff members. The patient was also loudly protesting any use of medications. As a medical student, I had encountered patients who were agitated, but this moment felt vastly different because I was now tasked with addressing the problem. I still remember how my muscles tensed out of anxiety. As the attending took the lead in talking with the patient, the situation continued to escalate. The patient's agitation was preventing them from being able to safely cooperate with staff despite our efforts at verbal de-escalation. As several staff members stayed with the patient, my attending and I went back to the workroom, where she instructed me to place orders for emergent medications. I sat there, an anxious intern with the solemn power and responsibility to order medications that might need to be

administered against the will of an agitated patient. The moment was surreal.

\section{A harsh reality}

I had envisioned my first day of residency to be quite different. I had expected to sit with patients, healing them by listening to their stories and giving them the attention they deserved. But instead, I found myself nervously inputting medication orders, checking and rechecking that the doses and administration routes were accurate-all the while knowing that the patient would likely refuse the medications. If that occurred, the patient would need to be held by staff so the medications could be administered. Although I knew that administering emergent medications was the appropriate clinical decision to prevent harm to the patient and others, I felt conflicted by acting in opposition to the patient's wishes. In that moment, intoxication or illness compromised patient autonomy for the sake of beneficence. I struggled with a creeping sense of guilt.

Although I did not have the chance to interact with this specific patient again, I often reflect on that encounter. I have learned that at times, the use of emergent

LET YOUR VOICE BE HEARD

CURRENT PSYCHIATRY invites psychiatry residents to share their views on professional or clinical topics for publication in Residents' Voices. E-mail jbauer@mdedge.com for author guidelines.

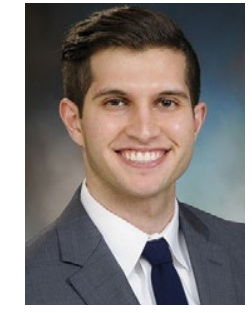

Dr. Khonsari is a PGY-2 Psychiatry Resident, Department of Psychiatry, University of Texas Southwestern, Dallas, Texas.

\section{Disclosure}

The author reports no financial relationships with any companies whose products are mentioned in this article, or with manufacturers of competing products.

doi: $10.12788 /$ cp.0047 
Clinical Point

I will approach

every encounter

with my patients

as an opportunity

to understand their

goals for care medications or court commitments for medication administration or hospitalizations is necessary. Since that first shift, I have cared for many other patients who have received emergent medications under similar circumstances. I have observed that such treatment often stabilizes patients and enables me to engage them in meaningful conversation to optimize their care.

\section{Lessons learned}

While some of what I have experienced during my training has made me uncomfortable, I have taken with me several valuable lessons. When a patient's intoxication or illness prevents shared decision-making, our focus as physicians should remain on the patient's safety, health, and well-being. It is necessary to engage patients in conversations to enable us to understand what ails them and promptly determine the right treatment, tailored to their specific needs and goals.

Moving forward, I know that I will encounter many more similar situations. I hope to position myself quickly and safely alongside agitated patients to engage them in shared decision-making. As a physician, I will approach every encounter with my patients as an opportunity to understand their goals for care, and empower them to make informed decisions regarding their treatment. 